\title{
Approach of the Corpus Research on Medical English Prepositions
}

\author{
Chongya Liu \\ Nanyang Institute of Technology, Henan, China, 473000
}

Keywords: Corpus; medicine; English; preposition

Abstract: It has become a common understanding in linguistic circles to let corpus speak. Real corpus combined with rational analysis is not only a language study but also an important way to learn English vocabulary. Corpus has great potential in medical English vocabulary teaching. Through corpus retrieval software, students can be guided to analyze, imitate, learn and apply real and natural corpus step by step, which can greatly improve the efficiency of medical English vocabulary learning.

In medical English teaching, the role of vocabulary teaching is far beyond people's imagination. If language structure is compared to the skeleton of language, it is vocabulary that provides important organs and flesh for language (Charmer, 1990:158). If a person does not understand grammar, he may be able to express a little thought in words, but if there is no word, no meaning can be expressed. To some extent, a college student's English proficiency mainly depends on his vocabulary and his mastery of vocabulary. Grammar is just "the glue that binds words together". For medical students, the biggest obstacle to learning medical English is not grammar but medical vocabulary.

According to statistics, about 75\% of medical English terminology is derived from Greek and Latin. Many medical terms are composed of Greek and Latin morphemes such as root, stem, affix and so on. Due to the particularity and professionalism of medical English vocabulary terms, our medical English teaching pays more attention to vocabulary teaching and learning, but the teaching effect is generally not ideal, and there is still much room for improvement. Therefore, how to make medical students express their ideas clearly, accurately, fluently and appropriately in different situations, environments and contexts, help them expand their vocabulary and increase their knowledge of medical vocabulary is a top priority. This paper mainly discusses the advantages, methods and specific cases of corpus in medical English vocabulary teaching, hoping to bring enlightenment to the field of medical English teaching.

\section{Advantages of corpus in vocabulary teaching}

Corpus is a large-scale electronic database which uses computer technology to process a large number of natural language materials (including p reprocessing, automatic grammar encoding, automatic parsing, semantic analysis, etc.) and store them for automatic retrieval, indexing and statistical analysis. It is a language database established for a specific purpose in accordance with clear design criteria. At present, the purpose of corpus building is becoming more and more 
professional. Various special-purpose corpora are emerging, such as newspaper English corpus, spoken English corpus, learner English corpus, corpus for phonetic analysis, test English corpus, comparative parallel corpus for translation research, scientific English corpus, medical English corpus, etc. As medicine is a huge subject, with the continuous development of medical English corpus, there are many sub-types of corpus, such as nursing English corpus, neurosurgery English corpus, Abstract corpus of medical papers, TCM English corpus and so on. Vocabulary teaching is one of the earliest and most fruitful fields in which corpus resources and research methods have been applied to foreign language teaching. The main advantages of corpus in vocabulary teaching are as follows:

\subsection{Real corpus, restoring context}

A great advantage of corpus is that it can provide real context. A corpus is a database of natural texts. The central task of English teaching is to cultivate interlanguage communicative and applied abilities necessary for their future career. True language input should be an effective way to cultivate their abilities. Therefore, the natural texts of corpus constitute an important resource for English teaching. Many English textbooks in China generally lack authentic communicative corpus of native English speakers. The emergence of corpus has largely alleviated this contradiction and can provide authentic corpus and real context for teaching.

\subsection{Word frequency statistics, key words}

According to cognitive learning theory, providing meaningful relationships and context in learning content can help learners to find clues when recalling, and more easily incorporate the learning content into the existing knowledge network, so as to facilitate understanding and memory. The advantage of corpus is that it can carry out word frequency statistics and acquire the required examples and key words. Teachers can use the frequency statistics function of corpus to make a list of key teaching vocabulary more scientifically, so that students can learn vocabulary more pertinently. In addition, the KWIC function can also be used to input keywords for full-text retrieval, from a large number of examples to obtain information about the use patterns of keywords, thus compiling exercises to help students review and consolidate.

\subsection{Vocabulary analysis and collocation}

Another advantage of corpus is that it can analyze synonyms and master the collocation of related words. Teachers can extract a large number of real examples from large corpus to distinguish and reveal the inherent rules and differences of language. This kind of analysis is very intuitive, and students will be more impressed. At the same time, it can fully mobilize enthusiastically and initiative in language learning. In addition, teachers can encourage students to learn independently after class, find their own weak vocabulary collocation through online corpus, expand English expression and improve their comprehensive English application ability. The research shows that students can make clear the meaning of vocabulary and internalize it through their own efforts, and the learning effect is better.

\section{Application of Prepositions in Medical English}

\subsection{Strong collocation of prepositions}

Like other styles, most of the idioms in medical English are composed of prepositions and other 
words. Prepositions can form phrases or idioms with verbs, nouns and adjectives. The following is illustrated with the prepositions "to" and "from". As shown in Table 1.

Table 1. Collocation of t o with various parts of speech and various collocations of From

\begin{tabular}{|l|l|}
\hline Noun + to & The patient made no response to maltreatment. \\
\hline Adjective+ to & The patient may be subject to further at-tack of fever. \\
\hline $\begin{array}{l}\text { Past participle } \\
+ \text { to }\end{array}$ & $\begin{array}{l}\text { Radiation is suitable for superficial malign-fancier confined to the } \\
\text { vocal cord. }\end{array}$ \\
\hline Verb + to & $\begin{array}{l}\text { The mechanism whereby genetic factors contribute to ulceration in } \\
\text { these families is unclear. }\end{array}$ \\
\hline $\begin{array}{l}\text { Various } \\
\text { collocations of } \\
\text { F r o m }\end{array}$ & $\begin{array}{l}\text { About } 30 \sim 60 \text { percent of patients suffer-ING from chronic } \\
\text { lymphoid leukemia have severe degree of acquired hypo gamma } \\
\text { globulin. }\end{array}$ \\
\hline
\end{tabular}

\subsection{Different collocations of prepositions produce different meanings}

Table 2. Different prepositional collocations produce different meanings

\begin{tabular}{|l|l|}
\hline \multirow{2}{*}{$\begin{array}{l}\text { The same preposition } \\
\text { collocates with different } \\
\text { other words }\end{array}$} & $\begin{array}{l}\text { The patient's mother died suddenly Fromm unknown cause } \\
\text { in her } 60 \text { 's. }\end{array}$ \\
\cline { 2 - 3 } & $\begin{array}{l}\text { Bronchitis differs from chronic baron-chit in that the former } \\
\text { is more of a localized dis-ease. }\end{array}$ \\
\hline $\begin{array}{l}\text { Different prepositions } \\
\text { collocate with the same } \\
\text { other words }\end{array}$ & $\begin{array}{l}\text { The activation of these two pathways re-cult in elevated } \\
\text { blood levels of specific hormones,namely,colitis and the } \\
\text { chatelaines. }\end{array}$ \\
\cline { 2 - 3 } & $\begin{array}{l}\text { Hydro's may result either from resoluteness collectivist or } \\
\text { from cystic duct obstruction inflammation. }\end{array}$ \\
\hline
\end{tabular}

As shown in Table 2, It shows that different prepositional collocations have different meanings. Therefore, when reading English medical materials or writing papers, we should pay great attention to the collocation of prepositions, otherwise we will misunderstand others.

\subsection{Prepositions often undergo part-of-speech conversion in Chinese translation}

There are many similarities in parts of speech between English and Chinese, such as nouns, verbs, adjectives and adverbs. But there are also some differences, such as articles, participles, gerunds, infinitives, relational pronouns and adverbs. Nouns and prepositions are widely used in English, and many of the words expressing action concepts are expressed by nouns or prepositions. Therefore, the corresponding transformation must be made in Chinese translation. This paper talks about the part-of-speech conversion of medical English prepositions in Chinese translation, that is, they are translated into Chinese verbs to express actions or actions.

\subsection{Misunderstanding of prepositions leads to errors in writing and translation}

When medical workers write medical papers or translate articles in English, if they cannot accurately use prepositions, they will make mistakes in sentence writing or English-Chinese translation.

For example:

(F) He received a vaccination of smallpox at six months of age.

(T) He received a vaccination against smallholding six months of age. 
"Vaccine (or vaccination) a against a disease" should be said that "vaccine a-against" or "vaccination a against" cannot be replaced by the preposition "of".

\section{Approaches to Corpus-based Teaching of Applied Medical Vocabulary}

\subsection{Making frequency list of medical terminology}

Medical science is a subject with many branches and huge knowledge. It is impossible and unnecessary for a medical student to master all the terms. So what medical vocabulary should we learn? What vocabulary should we learn first and what vocabulary should we learn later? This requires a relatively objective criterion to tell medical students which vocabulary is necessary, which is learn able or not, which is needed to learn in University and which is needed to learn in postgraduate stage. At present, the most real and effective way is to build a medical English corpus, and then build a medical terminology frequency table, using the highest frequency of 3000-5000 terms as the required vocabulary for medical undergraduates.

The syllabus of medical terminology can be made according to the students of different majors. For example, the students of clinical medicine must master the most common 5,000 words, while the students of nursing specialty only need to master the most common 3,000 words. Then, a corpus of medical English is established according to different branches of learning to develop a frequency list of related terms. For example, English terminology for pediatric medicine is developed for students majoring in pediatrics, and English terminology for surgical medicine is developed for students majoring in surgery.

\subsection{Providing authentic and natural vocabulary learning corpus}

Besides word frequency list, corpus can also provide real and natural language materials directly for vocabulary teaching activities. A word learning usually includes four levels, the first level is reading and writing; the second level is to see that the word can identify meaning; the third level is to understand and understand in a specific context; the fourth level is to be able to flexibly use in various communicative situations. If you only see a term that can read and write, just read and spell it repeatedly; if you want to know the meaning of the word, you must consult the dictionary of terms and remember the meaning of the dictionary repeatedly; if you want to ensure that every time you encounter the word in reading, you can recognize its contextual meaning, you must constantly recognize it in the context.

\section{Conclusion}

To sum up, in medical English, prepositions have a wide range of flexible meanings, strong collocation, wide uses and are difficult to grasp. Understanding the characteristics of prepositions and mastering their usage will help us to understand medical English literalness correctly, write authentic medical papers in English or translate advanced technology from foreign medical circles into Chinese, thus contributing to the medical cause of our country.

\section{References}

[1] Yang Zhengzhou. Introduction to Corpus Linguistics [M]. Shanghai: Shanghai Foreign Language Education Press, 2004.

[2] Bhang Wending. Application of Corpus in College English Vocabulary Teaching [J]. Chinese Journal, Foreign Language Education and Teaching, 2010 (3): 164-165.

[3] Ca Chunking. An analysis of College Autonomous learning driven by medical English corpus data [J]. Journal of 
Taiyuan City Vocational and Technical College, 2017 (11): 167-168.

[4] Araguaya. Establishment and application of small corpus of English original textbooks for medical specialty [J]. Medical education management, 2017 (S2): 23-25.

[5] Duo Shenyang, Yang Singsong. Construction and application of dynamic corpus for graduation theses of medical English major [J]. Journal of Iguanodon Medical College, 2014 (5): 746-747. 